\title{
Learning Accounting in Italy: An Empirical Inquiry into Student Voice
}

\author{
Giorgio Mion* \\ Department of Business Administration \\ University of Verona, Verona, Italy \\ Angela Broglia \\ Department of Business Administration \\ University of Verona, Verona, Italy \\ Claudio Girelli \\ Department of Human Sciences \\ University of Verona, Verona, Italy \\ Luisa Capparotto \\ Department of Human Sciences \\ University of Verona, Verona, Italy
}

\begin{abstract}
Students' perspective on learning accounting is an important factor to improve teaching approach and to develop a good learning path. This paper address a research gap on learning accounting in Italian Upper Secondary School (USS) by analysing students' perspective through a qualitative approach based on grounded theory. The paper presents research that employs the student-voice approach by analyzing 179 higher education students' narratives about their experiences with learning accounting during USS. Content analysis highlighted four material spheres of interest: characteristics of an effective teacher; specificity of learning accounting; work in class; and evaluation, experienced as a critical phase of learning process. The research is exploratory, but provides some first evidence that is useful for teacher training and developing further research. Although the research focuses in the Italian context, it crosses the national border, and can be useful to a broader debate on accounting education.
\end{abstract}

Keywords: student voice; accounting education; economiaaziendale, Italian Upper Secondary School, qualitative research

\section{Introduction}

Scientific debate about teaching and learning in secondary school is generally provided from different perspectives; for example, understanding the efficacy of teaching (Allan, Clarke, \& Jopling, 2009; Çimer, Odabaş Çimer, \& Vekli, 2013; Harris, 1998; Ko \& Sammons, 2013; Reynolds, 2008) or exploring specific problems in teaching (Avramidis \& Norwich, 2002; McMahon, Stoll, Thomas, Wallace, \& Bolam, 2006). In contrast, the debate on teaching single disciplines in Upper Secondary School (USS) is well developed in several disciplines, for example, in mathematics, science, and music. However, there are few or no systematic studies on accounting education in specific reference to the Italian context. In fact, according to Italian scientific tradition, EA is a composite unique discipline that includes both accounting and management studies. Italian USS is the third cycle of mandatory education; it usually has a duration of five years, and is attended by students from 14 to 19 years of age.

Given the absence of systematic debate on approaches to learning accounting in Italy and in particular on students' perspective on this topic, the present paper aims to examine this partially unexplored field by adopting the qualitative research approach of student voice and by basing the findings on empirical evidence. The study aims to uncover the educational past of students to infer some first observations of general validity that can contribute to developing the debate about disciplinary learning of accounting. The research approach is interdisciplinary, and combines pedagogic knowledge and competences with disciplinary research on accounting education. The cross-sectoral approach to the research aims to analyze the versatility of the teaching profession. The USS teacher is concurrently an educator and a teacher of a specific subject, and must combine different synergic skills to fulfil these roles. The interdisciplinary research approach adopted by this study allowed analysis of empirical evidence from different perspectives and allowed different aspects of being USS teacher, in particular an EA teacher, to be highlighted. 
The research considers that students are not only the principal stakeholders of teachers' work, but also the real coprotagonist of school. Consequently, understanding students' perspective on learning accounting is a crucial step to develop a solid learning path, capable to build robust disciplinary and transversal skills. The understanding of students' perspective is fundamental to develop research in accounting education.

The general aim of this paper is to understand how students understand learning accounting and which the determinant of a successful learning process is, in their opinion. To reach these research goals, the research asked students in their first year of a bachelor's degree to describe their experiences with EA learning during USS. As stated, the research methods are qualitative and adopt a grounded-theory approach to analyzing student voice. Seeking the perspective of students that have already begun their bachelor's degree allows examination of their past training because they are experimenting with their skills in academic context and they are more capable to evaluate their scholastic experience in the light of the so-called "school of competences". The sample is large and diverse, but is only a part of a much larger sample, not yet explored by research; for this reason, the analysis assumes an exploratory nature.

\section{Student Voice and Accounting Education: Literature Review}

Present research is based on students' experiences as direct witnesses to gain understanding of their training. Students' perspective is crucial in accounting education (Bandura \& Lyons, 2012) and, in general, in pedagogy, because the student is at the center of educational research because they are the principal actor of the school, or better stated, the coprotagonist of the teaching and learning process, with a role that equal to that of the teacher. In other words, student is not only the receiver of teachers' service, but it has specific responsibility and this factor is crucial in term of modern theory of knowledge (Bereiter, 2002).

Our research is anchored in student voice, a research strategy that was developed at the beginning of the 2000s in North America (Cook-Sather, 2002; Doddington, Flutter, \& Rudduck, 2007; Fielding, 2001; Flutter, 2006; Levin, 2000), but has been adopted in the Italian context (e.g. Dettori, 2013; Gemma \& Grion, 2016; Grion \& Alison, 2013; Ianes, Cappello, \& Demo, 2017; Zuccoli, 2013).

From the position of student voice, the student is an important source of information about teaching and learning, and has the capability to identify possibilities for improvement in teaching and learning. The research strategy of student voice places great trust in the student's perspective, and requires acknowledging the student perspective on learning as valid and constructive (Groves \& Welsh, 2010). The perspective of students on teaching and learning is deeply rooted in daily experience, and thus using this perspective for research on teaching and learning allows research to avoid the risk of discussing critical educational issues in detached or theoretical terms (Cook-Sather, 2002). For example, the previous study by Duarte (2013) adopted students' point of view to understand the factors that affect the effectiveness of teaching.

Previous studies adopted student voice methodology to understand a different view on teaching and they compared students' and teachers' perception on the same topics (e.g. Könings et al., 2014; Mitchell, Bradshaw, \& Leaf, 2010).

In the context of accounting education, researchers have principally demonstrated interest in student voice in the academic context (Hoque, 2002; Lindquist \& Olsen, 2007; Lord \& Robertson, 2006; McVay, Murphy, \& Yoon, 2008; Weil, Oyelere, \& Rainsbury, 2004). Most previous research focuses on the use of specific techniques or methods whose efficacy students are asked to evaluate. Other research asks students to understand their approach to teaching accounting (Mustafa, 2011; Sharma, 2002), which is often considered a difficult school subject and is marked by a prejudice of complexity (Mladenovic, 2002). More recently, Douglas and Gammie (2019) faced the approach of accounting degrees to non-technical skills.

\section{Institutional Framework}

EA can be considered a mixture of accounting and management (and partially organizational theory), EA is a unicum ifcompared to scientific international overview, and is the epistemological outcome of the so-called "manifesto" published by Gino Zappa (1927), who wanted to unify all previous studies on firms under one unique discipline.

However, the position of EA in Italian USS has evolved very slowly, and came to have a well-defined autonomous position as a specific discipline only in the school year 1996/1997. Before this time, EA was divided in two different subjects, of which accounting played a dominant role in relation to number of teaching hours and weight of final evaluation (graduation exam).

In Italy, accounting was introduced into USS by the Casati Law of 1859, and was confirmed by the Gentile Reform of schooling of 1923. This reform indelibly marked Italian USS through the implementation of the dichotomy between lyceums and technical institutes. The reform was developed by Giovanni Gentile (1875-1944), an idealist philosopher and minister of public instruction during the first years of fascism (1922-1924) (Gregor, 2017). 
The philosophy at the foundation of the of the Gentile Reform was the hierarchical superiority of classical studies over technical studies. The priority of classical studies worked not only at a theoretical level, but also at a practical one, for example, in the selection of top economic and political positions of employment.

After the inception of EA as a unitary science in school programs, the discipline remained divided into two nuclei (accounting and management) until the 1990s. The reform of USS, realized by Minister Gelmini in 2010, entered into force in the school year 2010/2011, but not even this reform modified the position of EA in Italian USS, and the discipline was included only in specific curricula. That is, the scholastic system designed by Giovanni Gentile did not change after Gelmini Reform, and EA is a subject taught only in technical schools.

EA has an important role in Istituti Tecnici Economici (Economic Technical Institutes) that have four principal curricula: Amministrazione Finanza Marketing (Administration Finance Marketing); Relazioni Internazionali per il Marketing (International Relations for Marketing); Sistemi Informativi Aziendali (Business Information Systems) and Turismo (Tourism). Ministerial guidelines attribute an important role to EA in these curricula, despite the minimum number of teaching hours of EA being different in the different curricula. For example, there is a minimum 264 hours of EA in the last year of Administration Finance Marketing, while the Tourism curriculum requires a minimum of only 132 hours. The real number of hours dedicated to a single subject is defined by the individual school based on the specific triennial didactical plan (Piano Triennale dell'Offerta Formativa.

During school year 2016/2017, there were 351,265 students enrolled in Economic Technical Institutes, which accounts for 13.4\% of all USS students in Italy. This number was slightly lower than that of the previous school year: 361,896 (13.8\%) (MIUR, 2018).

\section{Research Design}

The research adopts a phenomenological approach, aiming to explore students' perspectives on the analyzed phenomenon that is, learning EA in USS in Italy. We conducted data analysis adopting the methodological approach proposed by grounded theory (Glaser \& Strauss, 1967; Strauss \& Corbin, 1990). Consistently with the methodological approach, the research is guided by a wide research question: What is students' experience with EA learning during USS, and what implications can be derived for methods of teaching/learning from student voice?

Adopted methodological approach allows analysis of the educational fact without simplifying its nature or disclosing a definition (Mortari, 2007), but respecting its complexity as an endogenous characteristic. Data were analyzed as a starting point to formulate a theory on the phenomenon that aims to be a faithful interpretation of it.

Another important characteristic of the adopted research method is the circularity of the research path, that is, the research path does not have precise and consequential phases but is a "spiral path" (Mortari, 2007: p. 150). Data collection, analysis, and interpretation coexist in a unitary process of theoretical construction. That is, theorization on the phenomenon develops from data collection in such a way that it can improve the collection itself in a continuous and recursive analysis through the interdisciplinary research group.

Students who participated in the research have attained their USS degree. Therefore, they were able to narrate a realworld academic experience that can be used as a basis of comparison for defining their past scholastic experience. The conclusion of one learning experience through exiting the USS context, and the commencement of another learning experiencing through beginning a higher-education degree can help these students to develop of a more mature and critical perspective of their past experience (Van Wagoner, 2015).

We asked first-year students enrolled in a Bachelor of Economia Aziendale (Business Administration) or a Bachelor of Economia e Commercio (Economics and Commerce) at the University of Verona (in its two sites of Verona and Vicenza) to present a short, written text to narrate their EA learning experience in USS. Data collection was over a three-year period (academic years 2015/2016, 2016/2017, and 2017/2018). We put out the call for participation both orally during the lessons and through the students' e-learning platform. The natural addressees of the call were the students from Economic Technical Institutes or other technical schools that include EA in their curricula. Participation was voluntary and free, without any incentive or sanction. Therefore, the sample was self-defined by the students. 
The following is the text of the call for contributions.

Dear Student,

We are collecting data useful for understanding how EA is learned and taught in the USS. If you studied EA during your USS degree, we ask you to participate in our data collection by sending us a short, written text composed based on the following guidelines. Your contribution is valuable because it will allow us to collect experiences that are useful to research and teacher training, and to the improvement of teaching praxis.

\section{Guidelines}

Think about your experience as a USS student, particularly of learning EA, and narrate an episode that was notably meaningful in relation to this discipline. You can write freely, but if you do not know where to start, you can answer one or more of the following questions:

- Which issues do you consider most simply to understand? And which ones more difficult?

- Which types of lessons do you consider most effective (e.g., classroom teaching, exercises)

- Have you had teacher you found highly effective? In what ways were they like this?

- Did you need extra help in school to learn the discipline?

- Thinking over your five years in USS, were there any changes? If so, what types of changes? Did your approach to study changed?

Notes:

Please indicate your age and which school you attended.

There is no minimum or maximum word limit.

You can send more than one text.

If you prefer, you can send your contribution anonymously.

All narratives were made anonymous by assigning an alphanumeric code to each contribution.

The research group performed a content analysis of students' narratives using NVivo 11 software. The content analysis began by implementing an attentive and recursive reading of the narratives to recognize text units significant to the aims of the research. Each text unit was converted to a label, that is, "an enunciation-faithful to the content of starting text unit — that describes the essential quality without adding nothing nor interpreting" (Mortari, Dusi, Girelli, Sità, \& Tacconi, 2010, p. 52; tranlastion by authors). Labels allow different text units to be combined, including text units derived from different narratives.

By reading single labels repeatedly, and making reference to the content they represent, common sense units can be identified, and labels can be gathered into categories that can identify the phenomenon in its multiple aspects.

The construction of the coding considered the complexity of the students' experiences, which combine different dimensions as follows:

- the students' perception of themselves and their identity

- the students' relationship with the school as an institution (Goffman, 1961)

- the specificity of the students' experience with EA learning in the context of the global experience of being a USS student.

The research group maintained a distinction between these different dimensions of the students' experiences to ensure better focus on the issue. NVivo 11 software allowed the creation of a map of labels for each category, based on which, the research group participated in shared reflection and identified the following four categories:

1.characteristics of an effective teacher

2. learning EA/accounting

3. work in class

4. evaluation experience.

The results of the research are presented by adopting this structure of categories.

After the construction of the coding, four focus group were conducted with students to verify the analysis. The focus groups involved 30 students, chosen from among the students that contributed significant and complete narratives. The focus groups were recorded, and the content analysis was extended to the transcription of the dialogues from the focus groups. 


\section{Characteristics of the Sample}

The sample comprises 179 students enrolled in a Bachelor of Business Administration or a Bachelor of Economics and Commerce at the University of Verona in its two sites of Verona and Vicenza. Table 1 presents the distribution per academic year and per site.

Table 1: Distribution of students per academic year and per site

\begin{tabular}{|l|l|l|l|}
\hline Academic Year & Verona & Vicenza & Total \\
\hline $2015 / 2016$ & 49 & 17 & 66 \\
\hline $2016 / 2017$ & 25 & 34 & 59 \\
\hline $2017 / 2018$ & 24 & 30 & 54 \\
\hline Total & 98 & 81 & 179 \\
\hline
\end{tabular}

Most students came from the same province in which they were studying their bachelor's degree, but there were some exceptions of students coming from the bordering province of Padova or from the bordering regions of Lombardia, Trentino Alto Adige, and Emilia Romagna. Only one student came from another region (Puglia).The average age of the students is 19.3 years, and there were 104 female students and 75 male students.

\section{Results and Discussion}

\section{Characteristics of an effective teacher}

First, students' narratives made clear the essential relationship between the teacher and the taught subject. The students reported the belief that their own approach to the subject, level of passion for the subject, and even their academic success in the subject were a consequence of the capabilities of the teacher. Positive and negative experiences are present in the narratives, but all refer to the teacher's responsibility.

Among these six teachers, I found competent and willing ones, but also someone that showed they were anything but competent, and this variability caused a bad learning of the school subject. (6ECVR)

During the first year of USS, I hated this subject, only because I had an incompetent teacher that made me hate the subject. She did not explain anything, and demanded that we solve the exercises alone. During the second and third years, I had two other teachers, who much more competent and they made me love this subject (11ECVR).

In several narratives, students emphasized the importance of continuity of teaching, that is, having the same teacher for the five years of USS. Only few students experienced this, and the importance of developing a mutual relationship between the teacher and students as a solid approach to learning the subject emerged from their contributions:

Having the same teacher for the five years contributed to reinforcing my knowledge, and to learning better new concepts that were gradually introduced. (24EAVR)

However, several students had negative experiences in which they had to change to a different teacher, and continually restart from a mutual understanding between teacher and students. Therefore, the educational agreement at the basis of learning had to be renegotiated because it is very personal and linked to teaching and relational style of the teacher.

My learning path with EA has not been linear because I changed teacher every year. These continuous changes inevitably influenced my approach to the subject. On one hand, experiencing different teaching methods was stimulating, on the other hand, it prevented me from establishing a logic and temporal continuity among the different issues and learning methods. (67EAVI)

Among students' voices, there is also an outside one that underlines how the learning experience is individual despite having the same teacher. One student defines teacher continuity as an optimal, but not an indispensable condition for a good learning process, because the discriminating factor for academic success is autonomous study.

For five years, apart from the first two, we always changed teacher. On one hand, this is not positive because each teacher has their own rules and logical thread. On the other hand, it is not completely negative because we have had the opportunity to understand that there is no unique universal teaching method, but there are different models. (47EAVI)

If a teacher is an indispensable condition to having a good approach to the subject, the research group identified the characteristics of "good teacher" from the students" narratives. Some of the students equate all teachers, beyond the single taught subject. In addition to teachers' solid disciplinary competences, students emphasize the importance of teacher communication skills, both for building a meaningful relationship with students and for effectively transferring the specific discipline using simple language. The students noted that one fundamental characteristic of the teacher is the capacity to control the class. 
There must be silence in the classroom. The teacher must be able to control the class, because students are not old enough to understand that what is learned in the classroom is important for them. Therefore, students go to school not to learn but to meet up with mates, ok? Therefore, if the teacher is able to control the class, you can concentrate on the issue, there is silence, the student raises their hand; if there is some doubt, it can be clarified [...] but, if I am doing the exercises and I speak to my schoolmate, it is not good! (24FG.5.25)

Another crucial characteristic of a good teacher is helpfulness as a part of communication skills. Students often note the importance of helpfulness because they are conscious of having their own difficulties in learning, and of being slow to learn, but they also affirm that they have experienced being intimidated by teachers who do not understand the real need underlying their difficulties or requests for help. Teacher helpfulness is described by students as the teacher's capacity to gather feedback from students about the learning process, and changing their teaching methods if they are not adequate or appropriate for the students. During a focus group, one student narrated the following episode:

In third year, a new teacher arrived. She used book reading as a teaching method [...] if someone did not understand, they could ask [...] Nonetheless, from a debate among friends, we understood that this method was not suitable for us. So, we asked her to make a short summary [of the text] at the beginning of the lesson because this might help us to better understand the lesson [...] she was very kind and helpful and accepted our proposal. (FG22.G2.41)

The students expressed that there is no risk that helpfulness will result in the perception of "do-goodism". The awareness of the necessity to avoid overblown compliance is deeply rooted in students' thought because they consider an ineffective characteristic for productive learning. Thus, students value teacher sternness because it can stimulate productive learning.

Communication skills, helpfulness, and sternness are characteristics of a teacher that can build productive relationships with students through acknowledging students as playing a central role in their own learning path. When the teacher does not recognize the student's centrality, they are seen by the students as employing a didactic style inspired by a "sense of duty" rather than being based on the students' needs.

My last teacher had his program, his hours [...] and stop. His goal was to finish the program, not educate students. At least I thought that. (FG30.D.19)

\section{Learning EA/accounting}

The students' narratives allowed us to examine the students' perspectives on EA as a subject in which they had no competence before beginning USS. The students reflected on a learning path that led them to mature competences that are useful in an employment or higher-education context.

The importance of a unitary vision emerged in the students' narratives, that is, they felt that it is important to ensure the knowledge and competencies gained in each school year are not independent but are maintained during the five years of USS. EA was a subject in which, if you miss a part, you are in a bad position [...] at least, I experienced it like that. If you are not in step [with the rest of the class], you risk not understanding something important for being able to create a financial statement [which is understood as the final learning goal of EA]. (FG14.C.91)

The unity of the discipline becomes particularly clear at the end of the learning path, when what has been previously learned comes to light as being indispensable for learning further competencies and understanding the meaning of these. In the students' narratives, the understanding of this unity is often accompanied by a sense of satisfaction in learning and seems to foster a motivation to study:

An episode that changed my way of understanding the subject was when the teacher started to explain financial statements with the data of choice [...] I remember that I was impressed by how everything I had studied merged into this new type of exercise. Understanding was always satisfactory! (9ECVR)

Second, the dual nature (i.e., theoretical and practical) of EA was also emphasized by the students. The students expressed an understanding of the need to combine different learning methods: one to assimilate theoretical concepts and another to perform practical tasks by adopting problem-solving behavior. However, even if students recognized the importance of the theoretical dimension of the subject, they emphasized the importance of the practical dimension, and thus expressed that doing exercises was a favorite learning method.

The most effective lessons were the exercises because they combined practice and theory, and I was instantly able to understand the meaning of words by which teacher described an action. (21EAVR). The link between the subject and business reality is another characteristic of the discipline that fascinated the students, and one that formed the foundation of the students' commitment to continue studying accounting in higher education. This link allows the opportunity to connect what is learned at school to business and economic current events, and fosters the students obtaining keys to understanding specific accounting issues: 
We often read Il Sole 24 Ore [the most important Italian financial newspaper] in the first half hour of the week, after the teacher had examined the newspaper previously, he showed us the most interesting articles [...] Otherwise he did some case studies. For example, when we studied franchising, he used the Benetton case. (22 FG.M2.90)

Students emphasize that business reality has to be brought into the classroom in a concrete way, for example, by examining original documents. The students expressed that they did not want the teacher to use simplifications or generalizations that are often used in textbooks. Several students declared that they appreciate teachers who had practiced in the accounting profession if they were able to filter their experience, and make it useful learning material.

\section{Work in class}

Several opinions that favored active participation to lesson emerged in the narratives, and above all, in the focus groups. A teacher that provides students the opportunity to participate in class by expressing their opinion or asking questions was considered very effective.

I have found exchange of views with teacher and classmates very effective in learning some issues. (51ECVR)

In my opinion, the most productive lessons are those that require students' participation: no one loves listening to a teacher's speech for hours without expressing their own opinion. I think that if stimulated, students can better understand the meaning of what they are studying. An interesting method is submitting a problem to students [e.g., How to improve the corporate image of a specific firm] and letting them to find a solution. (2ECVR)

The students' narratives highlighted that their own awareness of the importance of class participation grew only towards the end of their course of studies, it was expressed that for most of the course, they had limited understanding of the value of their own class participation.

When you are 16 to 17 years old, you struggle to understand that participating is good. You mind your own business [...] but if you participate in the lesson, you learn better, but you only realize it at the end! Unfortunately! (FG22M2.48)

Together with lessons during which teacher captivates students through their explanation of the subject, there are experiences of other forms of student engagement, for example, the method of assigning students the task of presenting some parts of a lesson. In this method, students prepare subject issues autonomously at home and present them to the class in the following lesson. However, this method is not appreciated by all students for different reasons. First, because this method requires students to fulfil a task that they are not completely able to manage, above all because they are not used to conducting autonomous research outside using the internet, and they are not sufficiently skilled to detect whether the information they gather is correct.

I don't like presentations made at home by students. They can be in-depth analysis of issues already explained at school, but they cannot be totally new issues! Above all, if the teacher says, "Do not search on the internet"! So, where can we search for the information? So, we search on the internet anyway, but the information is a lot, and maybe wrong, and there is the risk we memorize the wrong information. (FG22.M1.48)

Further, there is the risk of this leading to incomplete learning of the subject because of the fragmentation of the program between different students, each of whom focuses only on its own part, without understanding the complex unity of the subject. In addition, some students who are particularly interested in accounting learning have to settle for classmates' explanations, which may not be correct. Some students considered this teaching method a strategy adopted by teacher to reduce their own workload by delegating teaching tasks to someone.

The teacher did not assign us a lot to do. She gave us some lessons to teach using the excuse of doing "research". In this way, each student studied a chapter and prepared a PowerPoint to show in class, but there was no sort of evaluation. The teacher sometimes commented on the slides. (46ECVR)

Teamwork was also reported as being often used, particularly for completing class exercises. Even if this practice is not always structured and used in an explicit cooperative learning strategy, students stated that they appreciated it and emphasized its positive characteristics. They particularly expressed that working in the context of their peer group allowed them to express their own doubts, which could be freely clarified by classmates because students are less intimidated by peers than they are by the teacher:

I can say that teamwork is of great use from a learning point of view. Even if it can sometimes seem like a waste of time, and is not always simple and needs a lot of time, teamwork helps the learning process because the best students help the other ones, and doubts can be mutually solved. Teamwork is also important from the point of view of relationships because it fosters a collaboration that can grow also outside of school time. (FG22G.2.1) 
In my opinion, the most effective lessons were the group exercises, because classmates have no scruples about asking each other questions that seem trivial (48EAVI).

Despite this positive account of teamwork, the discussions between the students in the focus groups demythologized the practice of teamwork in class. That is, it was found in the focus groups that if teamwork exercises are not well organized and controlled by the teacher, teamwork can be ineffective, or even counterproductive for student learning. During focus groups, the students particularly emphasized that there is a risk for the better or most motivated students not gain anything from teamwork because they needed to do extra work to compensate for the students in the group who did not do a great deal of work.

Regarding teamwork, I consider it a waste of time because it often happened that only two people in the group worked, while the other ones did not do anything. Therefore, in my opinion it is not so useful. (FG22.M1.11)

In my opinion, teamwork is useful only for those who are not in step with others in the class. On the contrary, it is detrimental for good students [...] It is a waste for time for those who have already learned the exercises, but obviously it is helpful for the other ones. But the usefulness is not for the best students. (FG24.5.32)

Nonetheless, according to the students' opinion, the effectiveness of the teamwork is not the responsibility of the less motivated students, but of the teacher. The students highlighted that the teacher has the responsibility to assign the appropriate role to each student and to guarantee the participation of all students. That is, teamwork cannot work autonomously within the student group, but requires attentive preparation and constant control of the teacher.

\section{Evaluation experience}

Evaluation was expressed as a problem for students. It emerges as a path often marked by the graduation exam: the teacher's action and the student's commitment to study are directed to an evaluation goal that sometimes seems to be the only goal expressed by the school during the five years.

I remember EA tests as huge weights. They lasted four hours! During the last year, we had to do entries, financial statements, balance-sheet reclassification. Achieving a unitary vision of the problem is right and helps understanding all issues, but to do all exercises in a test is really too much. We spent four to six hours doing a test! Even if it was to prepare for the final examination, I experienced this situation as too hard! (FG24.3.52)

Evaluation was expressed as problematic for the students. While some students emphasize that tests can foster individual commitment, others (above all, during focus groups) expressed that they would have preferred a more structured and transparent evaluation that could guarantee fairness and acknowledgment of individual merit.

A very popular need expressed among the students is for evaluation that provides them feedback about their learning path. It is interesting that some students expressed they sometimes received good evaluations without feeling like they had performed well. This type of experience was interpreted as a negative because they felt it allowed them to proceed through the course while not developing the skills useful for the graduation examinations, and above all, for employment or higher education:

During the fifth year, the teacher had a fixed range of evaluations for each student, and I always got eight or eight and a half [out of ten]. Even though I had not studied, I always got the same evaluation (FG30.DF.122). When I came to university, I had a wrong perception of my competence [...] even if my evaluations were high at USS, my competences were not. So, I had to restart from the basics. (FG30.S.192)

The students' narratives express a clear awareness of the value of evaluation, but they express the need for wellstructured and well-planned evaluations because evaluation should aim to measure individual skills effectively and foster self-assessment.

\section{Conclusions}

Although this study is exploratory, it has allowed some significant observations about learning accounting in Italian USS to be highlighted and the findings allow some general insights.

First, the students' narratives focus on the crucial role of the teacher in relation to both disciplinary competencies and relational skills. In the students' opinions, the teacher is an EA expert but also an educator, who should be capable of understanding the different needs of students and of building positive relationships with them. This underlines the importance of the initial training of teachers, about which in Italy there is a lack of continuity in training and recruitment models (Barzanò, 2009). Students are not conscious of the gaps in initial training, but the evidence extrapolated from their narratives focus on the problem of some teacher skills that cannot be derived only from disciplinary academic degrees, but also from a specific teaching training that allows maturing relational competences and other soft skills. 
In addition, the students made clear that EA/accounting has an important role in building professional skills in addition to cultural competences. Students consider EA a subject that builds a constant link between school and business reality, and thus EA characterizes their outgoing skills as practical ones. This professionalizing characteristic of EA affects the choice of learning methods by teachers in favor of practical exercises and case studies. However, the students expressed criticism of participative learning methods when they are applied without sufficient teacher planning and oversight. Particularly, such planning and oversight (or teacher responsibility) is considered by the students to create student engagement and enhance their individual contributions. If these participative learning methods are not well planned by the teacher, teamwork creates a double risk, that is, unfair workload distribution among students, and an ineffective learning opportunity for the best students.

Evaluation is considered by the students as an important phase of the learning path. It is expressed as being useful to enhance their skills, but only in the presence of two essential conditions: transparency of evaluation criteria and availability of self-assessment instruments.

The exploratory nature of this research calls for further in-depth analysis of a larger sample. Further, this research could be improved by analyzing student voice from an employment context. The qualitative analysis of a research "object" as complex as teaching and learning EA can be developed by adopting other methods of data collection (e.g. in-depth interviews, observations, etc.) that would allow a deeper exploration of students' perception of their learning process.

\section{References}

Abraham, A. (2006), Teaching and Learning in Accounting Education: Students' Perceptions of the Linkages between teaching Context, Approaches to Learning and Outcomes, in Celebrating Accounting edited by R. Juchau \& G. Tibbits, University of Western Sydney, 9-21.

Allan, J.,Clarke, K. and Jopling, M. (2009). Effective Teaching in Higher Education: Perceptions of First Year Undergraduate Students, International Journal of Teaching and Learning in Higher Education, 2009. International Journal of Teaching and Learning in Higher Education, 21(3), 362-372.

Avramidis, E., \& Norwich, B. (2002). Teachers' attitudes towards integration/inclusion: A review of the literature. European Journal of Special Needs Education, 17(2), 129-147. https://doi.org/10.1080/08856250210129056

Bandura, R. P., \& Lyons, P. (2012) Instructor Care and Consideration toward Students-What Accounting Students Report: A Research Note. Accounting Education, 21(5), 515-527.

https://doi.org/10.1080/09639284.2011.602511

Barzanò, G. (2009). Imparare e insegnare: teorie, strumenti, esempi. Milano: Bruno Mondadori.

Bereiter, C. (2002). Education and Mind in the Knowledge Age, Mahwah, NJ: Lawrence Erlbaum.

Çimer, A., Odabaş Çimer, S., \& Vekli, G. S. (2013). How does Reflection Help Teachers to Become Effective Teachers? International J. Educational Research (Vol. 1).

Cook-Sather, A. (2002). Authorizing Students' Perspectives: Toward Trust, Dialogue, and Change in Education. Educational Researcher (Vol. 31). https://doi.org/10.3102/0013189X031004003

Dettori, F. (2013). Migliorare la qualità della scuola superiore valorizzando il punto di vista degli studenti, in Student Voice: Prospettive internazionali e pratiche emergenti in Italia, edited by V. Grion and A. Cook-Sather, 242259. Milano: Edizioni Angelo Guerini.

Doddington, C., Flutter, J., \& Rudduck, J. (2007). Taking their word for it: Can listening, and responding, to pupils' views give new directions for school improvement? Education 3-13, 28(3), 46-51. https://doi.org/10.1080/03004270085200331

Douglas, S., \& Gammie, E. (2019). An investigation into the development of non-technical skills by undergraduate accounting programmes. Accounting Education, 28(3), 304-332. https://doi.org/10.1080/09639284.2019.1605532

Duarte, F. P. (2013), Conceptions of Good Teaching by Good Teachers: Case Studies from an Australian University, Journal of University Teaching \& Learning Practice, 10(1), 1-15.

Fielding, M. (2001). Students as Radical Agents of Change. Journal of Educational Change (Vol. 2). https://doi.org/10.1023/A:1017949213447

Flutter, J. (2006). 'This place could help you learn": Student participation in creating better school environments. Educational Review, 58(2), 183-193. https://doi.org/10.1080/00131910600584116

Gemma, C., \& Grion, V. (2016). Student Voice. Pratiche di partecipazione degli studenti e nuove implicazioni educative. Barletta: Cafagna Editore.

Goffman, E. (1961). Asylums: essays on the social situation of mental patients and other inmates. New York: Anchor Books. 
Gregor, J.A. (2017). Giovanni Gentile Philosopher of Fascism, New York: Routledge.

Grion, V., \& Alison, C.-S. (2013). Student voice - Prospettive internazionali e pratiche emergenti in Italia. Guerini Scientifica.

Groves, R., \& Welsh, B. (2010). The high school experience: What students say. Issues in Educational Research (Vol. 20).

Harris, A. (1998). Effective teaching: A review of the literature. School Leadership and Management, 18(2), 169-183. https://doi.org/10.1080/13632439869628

Hoque, Z. (2002). Using journal articles to teach public sector accounting in higher education. Journal of Accounting Education (Vol. 20). https://doi.org/10.1016/S0748-5751(02)00006-4

Ianes, D., Cappello, S., \& Demo, S. (2017). Teacher and student voices: a comparison between two perspectives to study integration processes in Italy, European Journal of Special Needs Education, 32(3),301313, https://doi.org/10.1080/08856257.2016.1223402

Ko, J., \& Sammons, P. (2013). Effective Teaching: A Review of Research and Evidence.

Könings, K. D., Seidel, T., Brand-Gruwel, S., \& van Merriënboer, J. J. G. (2014), Differences between students' and teachers' perceptions of education: profiles to describe congruence and friction, Instructional Science, 42(1), 11-30. https://doi.org/10.1007/s11251-013-9294-1

Levin, B. (2000). Putting students at the centre in education reform. Journal of Education Change, 1, 155-172. https://doi.org/10.1023/A:1010024225888

Lindquist, T. M., \& Olsen, L. M. (2007). How much help, is too much help? An experimental investigation of the use of check figures and completed solutions in teaching intermediate accounting. Journal of Accounting Education, 25(3), 103-117. https://doi.org/10.1016/j.jaccedu.2007.07.001

Lord, B. R., \& Robertson, J. (2006). Students' experiences of learning in a third-year management accounting class: Evidence from New Zealand. Accounting Education, 15(1), 41-59. https://doi.org/10.1080/06939280600581053

McMahon, A., Stoll, L., Thomas, S., Wallace, M., \& Bolam, R. (2006). Professional Learning Communities: A Review of the Literature. Journal of Educational Change, 7(4), 221-258. https://doi.org/10.1007/s10833-006-0001-8

McVay, G. J., Murphy, P. R., \& Yoon, S. W. (2008). Good practices in accounting education: Classroom configuration and technological tools for enhancing the learning environment. Accounting Education, 17(1), 41-63. https://doi.org/10.1080/09639280600843369

Mitchell, M. M., Bradshaw, C. P., \& Leaf, P. J. (2010). Student and Teacher Perceptions of School Climate: A Multilevel Exploration of Patterns of Discrepancy. Journal of School Health, 80(6), 271-279. https://doi.org/10.1111/j.1746-1561.2010.00501.x

MIUR (Minister of instruction, university, and research), Anagrafe nazionale degli student, http://dati.istruzione.it/espscu/index.html?area=anagStu, accessed on 23th March 2018.

Mladenovic, R. (2002). An investigation into ways of challenging introductory accounting students' negative perceptions of accounting. Accounting Education, 9(2), 135-155. https://doi.org/10.1080/09639280010000147

Mortari, L., Dusi, P., Girelli, C., Sità, C., \& Tacconi, G. (2010). Dire La pratica. La cultura del fare scuola. Milano: Bruno Mondadori.

Mustafa, A. (2011). Commercial High School Students' Conceptual Structures of Accounting. Far East Journal of Psychology and Business, 2(2), 24-36.

Reynolds, A. (2008). What Is Competent Beginning Teaching? A Review of the Literature. Review of Educational Research, 62(1), 1-35. https://doi.org/10.3102/00346543062001001

Sharma, D. S. (2002). Accounting students' learning conceptions, approaches to learning, and the influence of the learning-teaching context on approaches to learning. Accounting Education, 6(2), 125-146. https://doi.org/10.1080/096392897331532

Weil, S., Oyelere, P., \& Rainsbury, E. (2004). The usefulness of case studies in developing core competencies in a professional accounting programme: a New Zealand study. Accounting Education, 13(2), 139-169. https://doi.org/10.1080/09639280410001676602

Zappa, G. (1927). Tendenze nuove negli studi di ragioneria. Opening Speeach of the Accademic Year. Milano: Istituto editoriale scientifico.

Zuccoli, F. (2013). La pratica della discussione, una metodologia indispensabile per attivare la voce degli studenti, in Student Voice: Prospettive internazionali e pratiche emergenti in Italia, edited by V. Grion and A.CookSather, 212-231. Milano: Edizioni Angelo Guerini. 